\title{
Solutions of coupled problem of thermomechanics for electroconductive hollow cylinder under non-stationary electromagnetic action
}

\author{
Musij R., Drohomyretska Kh., Oryshchyn O. \\ Lviv Polytechnic National University \\ 12 S. Bandera str., 79013, Lviv, Ukraine
}

(Received 27 June 2017)

\begin{abstract}
A plane axisymmetrical coupled dynamic problem of thermomechanics for an electroconductive hollow cylinder under homogeneous non-stationary electromagnetic action is formulated. To construct its solution, the approximation of the determining functions the axial component of the magnetic field strength vector, the temperature, and the radial component of the displacement vector with respect to the radial variable - by cubic polynomials is used. As the result, the initial-boundary problem for determining functions is reduced to a Cauchy problem with respect to the time variable for the integral characteristics of these functions. The expressions of integral characteristics are obtained in the form of a convolution of functions describing the uniform solutions and the given limit values of determining functions. As an example, the amplitude-frequency characteristics of the radial stresses in the given cylinder are analyzed numerically, with taking into account the connectivity between the temperature and the displacement fields as well as without such accounting.
\end{abstract}

Keywords: coupled problem of thermomechanics, hollow electroconductive cylinder, nonstationary electromagnetic action, approximation; integral characteristics.

2000 MSC: $74 \mathrm{H} 10$

UDC: 539.3

\section{Introduction}

In exploitation of many devices, whose constructive element is a hollow electroconductive cylinder, such cylinder is subjected to the influence of non-stationary electromagnetic fields (EMF), including the one of the impulse nature [1]. Impulse electromagnetic field creates the volume non-stationary Joule heat sources $Q$ and ponderomotive forces $\boldsymbol{F}[2-6]$ in the cylinder. These two physical factors contribute to the appearance of the non-stationary temperature field $T$ and the field of mechanical movements $\boldsymbol{U}$. These fields are interconnected in general. In $[2,7-9]$ the investigation of thermostressed state (TSS) of a layer with plane-parallel boundaries under the heat action, under the induction heating caused by the steady EMF and under the action of impulsed EMF on account of thermostatic energy dissipation process is presented. However, the influence of impulsed EMF on thermomechanical behavior of the hollow cylinder taking to account the process of thermostatic energy dissipation was studied not enough.

In this paper, the mathematical formulation of the coupled dynamic problem of thermomechanics for a long hollow electroconductive cylinder under the homogeneous non-stationary electromagnetic action is considered. The method of its solving uses an approximation of distributions of all key functions over the thickness of the cylinder in radial variable $r$ by cubic polynomials and the integral Laplace transform in time $t$. The thermomechanical behavior of the cylinder under the electromagnetic impulse (EMI) action accounting the process of thermostatic energy dissipation and without such consideration is numerically investigated. 


\section{Mathematical formulation of the problem}

Let us consider a long hollow electroconductive cylinder reffered to the cylindrical coordinate system $(r, \varphi, z)$, the axis $O z$ of which coincides with the axis of symmetry of the cylinder. The material of the cylinder is homogeneous, isotropic and nonferromagnetic, and its physical and mechanical characteristics are constant. The cylinder is under the action of non-stationary EMF, which is given by the values of the axial component $H_{z}$ of the magnetic field stress vector $\boldsymbol{H}(r, t)$ on the inner $r=r_{0}$ and outer $r=r_{1}$ surfaces of the cylinder

$$
H_{z}\left(r_{0}, t\right)=H_{z}^{-}(t), \quad H_{z}\left(r_{1}, t\right)=H_{z}^{+}(t) .
$$

Here $H_{z}^{ \pm}(t)$ is the given time $t$ functions. The surfaces $r=r_{0}$ and $r=r_{1}$ of the cylinder are heat insulated and free of power loading.

Under these conditions, the estimated model for determination of thermostressed state of the cylinder has two stages: at the first stage from the equations of electrodynamics the magnetic field stress vector $\boldsymbol{H}$ in the cylinder and caused by it Joule heat ejection $Q$ and ponderomotive forces $\boldsymbol{F}$ are determined and at the second stage from the equations of connected dynamic problem of thermoelasticity the temperature field $T$ and the radial component $U_{r}(r, t)$ of the movement vector $\boldsymbol{U}=\left\{U_{r}(r, t) ; 0 ; 0\right\}$ and the corresponding components $\sigma_{j j}(j=r, \varphi, z)$ of the stress tensor $\hat{\sigma}$ are determined.

Based on the Maxwell's equations the nonzero axial component $H_{z}(r, t)$ of the magnetic field stress vector $\boldsymbol{H}=\left\{0 ; 0 ; H_{z}(r, t)\right\}$ can be determined from the equation

$$
\frac{\partial^{2} H_{z}}{\partial r^{2}}+\frac{1}{r} \frac{\partial H_{z}}{\partial r}-\sigma \mu \frac{\partial H_{z}}{\partial t}=0
$$

under the boundary conditions (1) and zero initial condition

$$
H_{z}(r, 0)=0 .
$$

Here $\sigma$ is the electroconductivity coefficient, $\mu$ is the magnetic penetration of material of the cylinder.

Using obtained function $H_{z}(r, t)$ the specific densities of Joule heat ejection $Q(r, t)$ and ponderomotive force $\boldsymbol{F}=\left\{F_{r}(r, t) ; 0 ; 0\right\}$ are presented in the form

$$
Q=\frac{1}{\sigma}\left(\frac{\partial H_{z}}{\partial r}\right)^{2}, \quad F_{r}=-\mu H_{z} \frac{\partial H_{z}}{\partial r} .
$$

The temperature $T(r, t)$ and radial component $U_{r}(r, t)$ of the movement vector are determined from the system of equations for the connected dynamic problem of thermomechanics for the cylinder

$$
\begin{gathered}
\frac{\partial^{2} T}{\partial r^{2}}+\frac{1}{r} \frac{\partial T}{\partial r}-\frac{1+\varepsilon_{x}}{\kappa} \frac{\partial T}{\partial t}-\varepsilon_{*} \frac{1+2 \nu}{\kappa \alpha E} \frac{\partial^{2} U_{r}}{\partial t \partial r}=-\frac{1}{\lambda} Q \\
\frac{\partial^{2} U_{r}}{\partial r^{2}}+\frac{1}{r} \frac{\partial U_{r}}{\partial r}-\frac{U_{r}}{r^{2}}-\frac{1}{c^{2}} \frac{\partial^{2} U_{r}}{\partial t^{2}}=\alpha \frac{1+\nu}{1-\nu} \frac{\partial T}{\partial r}-\frac{(1+\nu)(1-2 \nu)}{E(1-\nu)} F_{r}
\end{gathered}
$$

Here $\kappa, \lambda, \nu, \alpha$ are the temperature and the thermal conductivity coefficients, Poisson's coefficient, the linear thermal expansion coefficient; $E$ is the Young's constant; $\rho$ is the density of material of cylinder; $c=\sqrt{E(1-\nu) /(\rho(1+\nu)(1-2 \nu))}$ is speed of elastic wave of expansion; $\varepsilon_{*}$ is the parameter that characterizes the connectivity of strain and temperature fields.

The system (5) is solved under the boundary conditions

$$
\frac{\partial T\left(r_{0}, t\right)}{\partial r}=0, \quad \frac{\partial T\left(r_{1}, t\right)}{\partial r}=0
$$

Mathematical Modeling and Computing, Vol.4, No. 1, pp.69-77 (2017) 
of heat insulation of surfaces $r=r_{0}$ and $r=r_{1}$, conditions of absence of power loading on these surfaces

$$
\begin{aligned}
& \frac{\partial U_{r}\left(r_{0}, t\right)}{\partial r}+\frac{\nu}{1-\nu} \frac{U_{r}\left(r_{0}, t\right)}{r_{0}}=\alpha \frac{1+\nu}{1-\nu} T\left(r_{0}, t\right), \\
& \frac{\partial U_{r}\left(r_{1}, t\right)}{\partial r}+\frac{\nu}{1-\nu} \frac{U_{r}\left(r_{1}, t\right)}{r_{1}}=\alpha \frac{1+\nu}{1-\nu} T\left(r_{1}, t\right)
\end{aligned}
$$

and also zero initial conditions.

$$
T(r, 0)=0, \quad U_{r}(r, 0)=0, \quad \frac{\partial U_{r}(r, 0)}{\partial r}=0 .
$$

From the resulting functions $T(r, t), U_{r}(r, t)$, the radial $\sigma_{r r}$, circular $\sigma_{\varphi \varphi}$ and axial $\sigma_{z z}$ components of the stress tensor were determined by the expressions

$$
\begin{aligned}
\sigma_{r r} & =\frac{2 E}{1-2 \nu}\left[(1-\nu) \frac{\partial U_{r}}{\partial r}+\nu \frac{U_{r}}{r}-\alpha(1+\nu) T\right], \\
\sigma_{\varphi \varphi} & =\frac{2 E_{n}}{1-2 \nu}\left[(1-\nu) \frac{U_{r}}{r}+\nu \frac{\partial U_{r}}{\partial r}-\alpha(1+\nu) T\right], \\
\sigma_{z z} & =\nu\left(\sigma_{r r}+\sigma_{\varphi \varphi}\right)-\alpha E(1+\nu) T .
\end{aligned}
$$

\section{The method of solving the problem}

To construct the solutions of the described above initial boundary value problems of electrodynamics (1)-(3) and connected thermoelasticity (5)-(8), we use an approximation of determining functions in radial variable by cubic polynomials [10].

Solutions of defined above initial boundary value problems of electrodynamics (1)-(3) and connected thermoelasticity (5)-(8) were constructed using an approximation of determining functions $\Phi(r, t)=$ $\left\{H_{z}(r, t), T(r, t), U_{r}(r, t)\right\}$, in radial variable by cubic polynomials

$$
\begin{aligned}
H_{z}(r, t) & =\sum_{i=0}^{3} a_{i}(t) r^{i}, \\
T(r, t) & =\sum_{i=0}^{3} b_{i}(t) r^{i}, \\
U_{r}(r, t) & =\sum_{i=0}^{3} c_{i}(t) r^{i} .
\end{aligned}
$$

The coefficients $a_{i}(t), b_{i}(t), c_{i}(t)$ of approximation polynomials (10)-(12) are taken in the form of linear combinations

$$
\begin{aligned}
& a_{i}(t)=a_{i 1} H_{z 1}(t)+a_{i 2} H_{z 2}(t)+a_{i 3} H_{z}^{+}(t)+a_{i 4} H_{z}^{-}(t), \\
& b_{i}(t)=b_{i 1} T_{1}(t)+b_{i 2} T_{2}(t) \\
& c_{i}(t)=c_{i 1} U_{r 1}(t)+c_{i 2} U_{r 2}(t)+c_{i 3} T\left(r_{0}, t\right)+c_{i 4} T\left(r_{1}, t\right)
\end{aligned}
$$

and integral characteristics of axial component $H_{z}(r, t)$ of the vector $\boldsymbol{H}$

$$
H_{z s}(t)=\int_{r_{0}}^{r_{1}} H_{z}(r, t) r^{s+1} d r, \quad s=1,2
$$


the temperature $T(r, t)$

$$
T_{s}(t)=\int_{r_{0}}^{r_{1}} T(r, t) r^{s+1} d r, \quad s=1,2,
$$

the radial component $U_{r}(r, t)$ of the vector $\boldsymbol{U}$

$$
U_{r s}(t)=\int_{r_{0}}^{r_{1}} U_{r}(r, t) r^{s+1} d r, \quad s=1,2
$$

and functions that describe the limit values of determining functions $\Phi(r, t)$ on the surfaces $r=r_{0}$ and $r=r_{1}$ of the cylinder.

The equation for finding integral characteristics $H_{z s}(t)(s=1,2)$ of the function $H_{z}(r, t)$ is obtained by integration of the equation (2) according to the formula (16) and using expressions (10), (13). As a result, the system of equations for functions $H_{z s}(t)$ was obtained

$$
\left\{\begin{array}{l}
\frac{d H_{z 1}(t)}{d t}-d_{1} H_{z 1}(t)-d_{2} H_{z 2}(t)=d_{3} H_{z}^{+}(t)+d_{4} H_{z}^{-}(t), \\
\frac{d H_{z 2}(t)}{d t}-d_{5} H_{z 1}(t)-d_{6} H_{z 2}(t)=d_{7} H_{z}^{+}(t)+d_{8} H_{z}^{-}(t),
\end{array}\right.
$$

which according to (3) is solved for zero initial conditions.

Here

$$
\begin{aligned}
d_{l} & =\frac{1}{\sigma \mu} \sum_{i=1}^{3} \alpha_{i 1} a_{i l}, & d_{l+4} & =\frac{1}{\sigma \mu} \sum_{i=1}^{3} \alpha_{i 2} a_{i l}, \quad l=\overline{1,4} \\
\alpha_{i 1} & =\frac{i^{2}\left(r_{1}^{i+1}-r_{0}^{i+1}\right)}{i+1}, & \alpha_{i 2} & =\frac{i^{2}\left(r_{1}^{i+2}-r_{0}^{i+2}\right)}{i+2} .
\end{aligned}
$$

Bt integrating the system of equations (5) according to the expressions (17), (18) and using the representations (11), (12), (14), (15) we obtain the following system of four interconnected equations to determine the integral characteristics $T_{s}(t)$ and $U_{r s}(t)$, temperature $T(r, t)$ and radial movements $U_{r}(r, t)$.

$$
\left\{\begin{array}{l}
d_{3}^{*} \frac{d u_{r 1}}{d t}+d_{4}^{*} \frac{d u_{r 2}}{d t}+\beta_{1} \frac{d T_{1}}{d t}-d_{1}^{*} T_{1}-d_{2}^{*} T_{2}=R_{1}(t), \\
d_{9}^{*} \frac{d u_{r 1}}{d t}+d_{10}^{*} \frac{d u_{r 2}}{d t}-d_{7}^{*} T_{1}+\beta_{1} \frac{d T_{2}}{d t}-d_{8}^{*} T_{2}=R_{2}(t) \\
d_{13}^{*} u_{r 1}+d_{14}^{*} u_{r 2}-\frac{1}{c^{2}} \frac{d^{2} u_{r 1}}{d t^{2}}=\Phi_{* 1}(t) \\
d_{17}^{*} u_{r 1}+d_{18}^{*} u_{r 2}-\frac{1}{c^{2}} \frac{d^{2} u_{r 2}}{d t^{2}}=\Phi_{* 2}(t)
\end{array}\right.
$$

Here

$$
\begin{gathered}
R_{1}(t)=Q_{1}(t)-d_{5}^{*} \frac{d T\left(r_{0}, t\right)}{d t}-d_{6}^{*} \frac{d T\left(r_{1}, t\right)}{d t} ; \\
R_{2}(t)=Q_{2}(t)-d_{11}^{*} \frac{d T\left(r_{0}, t\right)}{d t}-d_{12}^{*} \frac{d T\left(r_{1}, t\right)}{d t} ; \\
Q_{s}(t)=\frac{1}{\lambda} \int_{r_{0}}^{r_{1}} Q(r, t) r^{s+1} d r, \quad s=1,2 ; \quad \Phi_{* s}(t)=\int_{r_{0}}^{r_{1}} \Phi_{*}(r, t) r^{s+1} d r, \quad s=1,2 ; \\
\Phi_{* 1}(t)=\Phi_{1}(t)-d_{15}^{*} T\left(r_{0}, t\right)-d_{16}^{*} T\left(r_{1}, t\right) ; \quad \Phi_{* 2}(t)=\Phi_{2}(t)-d_{19}^{*} T\left(r_{0}, t\right)-d_{20}^{*} T\left(r_{1}, t\right) ; \\
\Phi_{s}(t)=\int_{r_{0}}^{r_{1}} \Phi(r, t) r^{s+1} d r, \quad s=1,2 ; \quad \Phi(r, t)=\beta_{3} \frac{\partial T}{\partial r}-\beta_{4} F_{r},
\end{gathered}
$$


where

$$
\begin{aligned}
\beta_{1} & =\frac{1+\varepsilon_{*}}{\kappa}, \quad \beta_{2}=\frac{1+\nu}{\kappa \alpha T}, \quad \beta_{3}=\alpha \frac{1+\nu}{1-\nu}, \quad \beta_{4}=\frac{(1+\nu)(1-2 \nu)}{E(1-\nu)} \\
d_{1}^{*} & =\sum_{i=1}^{3} \alpha_{i 1} b_{i 1}, \quad d_{2}^{*}=\sum_{i=1}^{3} \alpha_{i 1} b_{i 2}, \quad d_{3}^{*}=\beta_{2} \sum_{i=1}^{3} \alpha_{i 3} c_{21}, \\
d_{4}^{*}= & \beta_{2} \sum_{i=1}^{3} \alpha_{i 3} c_{22}, \quad d_{5}^{*}=\beta_{2} \sum_{i=1}^{3} \alpha_{i 3} c_{i 3}, \quad d_{6}^{*}=\beta_{2} \sum_{i=1}^{3} \alpha_{i 3} c_{i 4}, \\
d_{7}^{*}= & \sum_{i=1}^{3} \alpha_{i 2} b_{i 1}, \quad d_{8}^{*}=\sum_{i=1}^{3} \alpha_{i 2} b_{i 2}, \quad d_{9}^{*}=\sum_{i=1}^{3} \alpha_{i 4} c_{21}, \\
d_{10}^{*}= & \sum_{i=1}^{3} \alpha_{i 4} c_{22}, \quad d_{11}^{*}=\beta_{2} \sum_{i=1}^{3} \alpha_{i 4} c_{i 3}, \quad d_{12}^{*}=\beta_{2} \sum_{i=1}^{3} \alpha_{i 4} c_{i 4}, \\
d_{13}^{*}= & \sum_{i=1}^{3} c_{i 1}\left(\alpha_{i 1}-\frac{r_{1}^{i+1}-r_{0}^{i+1}}{i+1}\right), \quad d_{14}^{*}=\sum_{i=1}^{3} c_{i 2}\left(\alpha_{i 1}-\frac{r_{1}^{i+1}-r_{0}^{i+1}}{i+1}\right), \\
d_{15}^{*}= & \sum_{i=1}^{3} c_{i 3}\left(\alpha_{i 1}-\frac{r_{1}^{i+1}-r_{0}^{i+1}}{i+1}\right), \quad d_{16}^{*}=\sum_{i=1}^{3} c_{i 4}\left(\alpha_{i 1}-\frac{r_{1}^{i+1}-r_{0}^{i+1}}{i+1}\right), \\
d_{17}^{*}= & \sum_{i=1}^{3} c_{i 1}\left(\alpha_{i 2}-\frac{r_{1}^{i+2}-r_{0}^{i+2}}{i+2}\right), \quad d_{18}^{*}=\sum_{i=1}^{3} c_{i 2}\left(\alpha_{i 2}-\frac{r_{1}^{i+2}-r_{0}^{i+2}}{i+2}\right), \\
d_{19}^{*}= & \sum_{i=1}^{3} c_{i 3}\left(\alpha_{i 2}-\frac{r_{1}^{i+2}-r_{0}^{i+2}}{i+2}\right), \quad d_{20}^{*}=\sum_{i=1}^{3} c_{i 4}\left(\alpha_{i 2}-\frac{r_{1}^{i+2}-r_{0}^{i+2}}{i+2}\right) \\
\alpha_{i 3}= & \frac{i\left(r_{1}^{i+2}-r_{0}^{i+2}\right)}{i+2}, \quad \alpha_{i 4}=\frac{i\left(r_{1}^{i+3}-r_{0}^{i+3}\right)}{i+3} .
\end{aligned}
$$

According to the conditions (8), the system of equations (20) is solved for zero initial conditions on integral characteristics $T_{s}(t)$ and $U_{r s}(t)$ of temperature $T(r, t)$ and radial motions $U_{r}(r, t)$.

To find solutions of the Cauchy problem for functions $H_{z s}(t), T_{s}(t)$ and $U_{r s}(t)$ that are described by systems of equations (19) and (20) at zero initial conditions on these functions, the integral Laplace transform in time variable $t$ is applied to equations of systems (19) and (20). Then systems of algebraic equations regarding to transformants of the functions $H_{z s}(t), T_{s}(t)$ and $U_{r s}(t)$ are obtained

$$
\begin{aligned}
& \left\{\begin{array}{l}
\left(p-d_{1}\right) \bar{H}_{z 1}(p)-d_{2} \bar{H}_{z 2}(p)=d_{3} \bar{H}_{z}^{+}(p)+d_{4} \bar{H}_{z}^{+}(p) \\
-d_{6} \bar{H}_{z 1}(p)+\left(p-d_{6}\right) \bar{H}_{z 2}(p)=d_{7} \bar{H}_{z}^{+}(p)+d_{8} \bar{H}_{z}^{-}(p),
\end{array}\right. \\
& \left\{\begin{array}{l}
d_{3} p \overline{u_{r 1}}+d_{4} p \overline{u_{r 2}}+\left(\beta_{1} p-d_{1}\right) \overline{T_{1}}-d_{2} \overline{T_{2}}=\overline{R_{1}(p)} \\
d_{9} p \overline{u_{r 1}}+d_{10} p \overline{u_{r 2}}-d_{7} \overline{T_{1}}+\left(\beta_{1} p-d_{8}\right) \overline{T_{2}}=\overline{R_{2}(p)} \\
\left(\frac{p^{2}}{c^{2}}-d_{13}\right) \overline{u_{r 1}}-d_{14} \overline{u_{r 2}}=\overline{\Phi_{* 1}(p)} \\
-d_{17} \overline{u_{r 1}}+\left(\frac{p^{2}}{c^{2}}-d_{18}\right) \overline{u_{r 2}}=\Phi_{2}(p) .
\end{array}\right.
\end{aligned}
$$


Here $p$ is the parameter of Laplace transform, and the top line describing the Laplace transformants of the respective functions.

The systems (21) and (22) are solved by Cramer's rule. We use Theorems of expansion and of the functions convolution to the obtained transformants of solutions of these systems. As the result the solutions of (19) are obtained in the form

$$
H_{z s}(t)=\sum_{k=1}^{2} \int_{0}^{t}\left[H^{+}(\tau) B_{s 1}(k)+H^{-}(\tau) B_{s 2}(k)\right] e^{p_{n}(t-\tau)} d \tau, \quad s=1,2
$$

where

$$
\begin{array}{ll}
B_{11}(k)=\frac{d_{3}\left(p_{k}-d_{6}\right)+d_{2} d_{7}}{2 p_{k}-\left(d_{1}+d_{6}\right)}, & B_{12}(k)=H^{-}(\tau) \frac{d_{4}\left(p_{k}-d_{6}\right)+d_{2} d_{8}}{2 p_{k}-\left(d_{1}+d_{6}\right)}, \\
B_{21}(k)=\frac{d_{7}\left(p_{k}-d_{1}\right)+d_{3} d_{5}}{2 p_{k}-\left(d_{1}+d_{6}\right)}, & B_{22}(k)=H^{-}(\tau) \frac{d_{8}\left(p_{k}-d_{1}\right)+d_{4} d_{5}}{2 p_{k}-\left(d_{1}+d_{6}\right)},
\end{array}
$$

$p_{k}$ are the roots of the characteristic equation $p^{2}-p\left(d_{1}+d_{6}\right)+d_{1} d_{6}-d_{2} d_{5}=0$.

Solutions of the system (20) have been written in the form

$$
\begin{aligned}
u_{r 2}(t) & =\sum_{n=1}^{6} \int_{0}^{t}\left[\frac{A_{3}\left(p_{n}\right) \Phi_{2}(\tau)-A_{4}\left(p_{n}\right) \Phi_{1}(\tau)}{\Delta^{\prime}(p)}\right] e^{p_{n}(t-\tau)} d \tau, \\
T_{1}(t) & =\sum_{n=1}^{6} \int_{0}^{t}\left[\frac{A_{5}\left(p_{n}\right) \Phi_{1}(\tau)-A_{6}\left(p_{n}\right) \Phi_{2}(\tau)+R_{1}(\tau) A_{7}\left(p_{n}\right)-R_{2}(\tau) A_{8}\left(p_{n}\right)}{\Delta^{\prime}\left(p_{n}\right)}\right] e^{p_{n}(t-\tau)} d \tau, \\
T_{2}(t) & =\sum_{n=1}^{6} \int_{0}^{t}\left[\frac{A_{10}\left(p_{n}\right) \Phi_{2}(\tau)-A_{9}\left(p_{n}\right) \Phi_{1}(\tau)-R_{1}(\tau) A_{11}\left(p_{n}\right)+R_{2}(\tau) A^{\prime} 12\left(p_{n}\right)}{\Delta^{\prime}\left(p_{n}\right)}\right] e^{p_{n}(t-\tau)} d \tau .
\end{aligned}
$$

Here

$$
\begin{aligned}
A_{1}(p)= & \frac{\beta_{1}^{2}}{c^{2}} p^{4}-\frac{\beta_{1}\left(d_{1}+d_{8}\right)}{c^{2}} p^{3}+\left(\frac{d_{1} d_{8}-d_{2} d_{7}}{c^{2}}-d_{18} \beta_{1}^{2}\right) p^{2}+\beta_{1} d_{18}\left(d_{1}+d_{8}\right) p+d_{18}\left(d_{2} d_{7}-d_{1} d_{8}\right), \\
A_{2}(p)= & -\beta_{1}^{2} d_{14} p^{2}+\beta_{1} d_{14}\left(d_{1}+d_{8}\right) p-d_{14}\left(d_{1} d_{8}-d_{2} d_{7}\right), \\
A_{3}(p)= & \frac{\beta_{1}^{2}}{c^{2}} p^{4}-\frac{\beta_{1}\left(d_{1}+d_{8}\right)}{c^{2}} p^{3}+\left(\frac{d_{1} d_{8}-d_{2} d_{7}}{c^{2}}-d_{13} \beta_{1}^{2}\right) p^{2}+\beta_{1} d_{13}\left(d_{1}+d_{8}\right) p+d_{13}\left(d_{2} d_{7}-d_{1} d_{8}\right), \\
A_{4}(p)= & -\beta_{1}^{2} d_{17} p^{2}-\beta_{1} d_{17}\left(d_{1}+d_{8}\right) p+d_{17}\left(d_{2} d_{7}-d_{1} d_{8}\right), \\
A_{5}(p)= & -\frac{\beta_{1} d_{3}}{c^{2}} p^{4}+\frac{d_{3} d_{8}-d_{2} d_{9}}{c^{2}} p^{3}+\beta_{1}^{2}\left(d_{3} d_{18}-d_{4} d_{17}\right) p^{2} \\
& +\left(d_{2} d_{9} d_{18}-d_{2} d_{10} d_{17}-d_{3} d_{8} d_{18}-d_{4} d_{8} d_{17}\right) p+d_{3} d_{8} d_{18}, \\
A_{6}(p)= & \frac{\beta_{1} d_{4}}{c^{2}} p^{4}+\frac{d_{2} d_{10}-d_{4} d_{8}}{c^{2}} p^{3}+\beta_{1}\left(d_{3} d_{14}-d_{4} d_{13}\right) p^{2}+d_{13}\left(d_{4} d_{8}-d_{2} d_{10}\right)+d_{14}\left(d_{2} d_{9}-d_{3} d_{8}\right) p, \\
A_{7}(p)= & \frac{\beta_{1}}{c^{4}} p^{5}-\frac{d_{8}}{c^{4}} p^{4}-\frac{\beta_{1}\left(d_{13}+d_{18}\right)}{c^{2}} p^{3}+\frac{d_{8}\left(d_{13}+d_{18}\right)}{c^{2}} p^{2} \\
& +\beta_{1}\left(d_{13} d_{18}-d_{14} d_{17}\right) p+d_{8}\left(d_{14} d_{17}-d_{13} d_{18}\right), \\
A_{8}(p)= & -\frac{d_{2}}{c^{2}} p^{4}+\frac{d_{2}\left(d_{13}+d_{18}\right)}{c^{2}} p^{2}+d_{2}\left(d_{14} d_{17}-d_{13} d_{18}\right) ;
\end{aligned}
$$

$p_{n}$ are the roots of the characteristic equation

$$
\Delta(p)=a_{6} p^{6}+a_{5} p^{5}+a_{4} p^{4}+a_{3} p^{3}+a_{2} p^{2}+a_{1} p^{1}+a_{0}=0,
$$


where

$$
\begin{aligned}
& a_{0}=d_{2}^{*} d_{7}^{*} d_{14}^{*} d_{17}^{*}-d_{2}^{*} d_{7}^{*} d_{13}^{*} d_{18}^{*}+d_{1}^{*} d_{8}^{*} d_{13}^{*} d_{18}^{*}+d_{1}^{*} d_{8}^{*} d_{14}^{*} d_{17}^{*}, \\
& a_{1}=\beta_{1}\left(d_{1}^{*}+d_{8}^{*}\right) d_{14}^{*} d_{17}^{*}-\beta_{1}\left(d_{1}^{*}+d_{8}^{*}\right) d_{13}^{*} d_{18}^{*}, \\
& a_{2}=\frac{d_{2}^{*} d_{7}^{*}\left(d_{13}^{*}+d_{18}^{*}\right)}{c^{4}}-\frac{d_{1}^{*} d_{8}^{*}\left(d_{13}^{*}+d_{18}^{*}\right)}{c^{2}}+\beta_{1}^{2}\left(d_{13}^{*} d_{18-}^{*} d_{14}^{*} d_{17}^{*}\right), \\
& a_{3}=-\frac{\beta_{1}}{c^{2}}\left(d_{1}^{*}+d_{8}^{*}\right)\left(d_{13}^{*}+d_{18}^{*}\right), \\
& a_{4}=-\frac{d_{2}^{*} d_{7}^{*}\left(d_{13}^{*}+d_{18}^{*}\right)}{c^{2}}+\frac{d_{1}^{*} d_{8}^{*}}{c^{4}}+\frac{\beta_{1}^{2}}{c^{2}}\left(d_{13}^{*}+d_{18}^{*}\right), \\
& a_{5}=-\frac{\beta_{1}}{c^{4}}\left(d_{1}^{*}+d_{8}^{*}\right), \quad a_{6}=-\frac{\beta_{1}^{2}}{c^{4}} .
\end{aligned}
$$

Substituting expressions (23)-(24) into (10)-(15), we obtain the general solution of the coupled problem of thermomechanics for the considered electroconductive cylinder under homogeneous nonstationary electromagnetic action.

\section{Investigation of amplitude-frequency characteristics of radial stresses under ampli- tude modulated radioimpulse (AMRI)}

The AMRI action is mathematically described by the function [11]

$$
H_{z}^{ \pm}(t)=k H_{0}\left(e^{-\beta_{1} t}-e^{-\beta_{2} t}\right) \cos \omega t .
$$

Here $k$ is a normalizing factor; $H_{0}$ is the maximum value of the magnetic field stress on the surfaces $r=r_{0}$ and $r=r_{1} ; \beta_{1}$ and $\beta_{2}$ are parameters corresponding to times of fronts growth $\tau_{\text {iner }}$ and decay $\tau_{\text {decr. }}$ of AMRI; $\omega$ is the frequency of withstanding electromagnetic waves. Substituting (26) into the obtained expressions of integral characteristics (23)-(24) and using formulas (10)-(15) we can write down the solution of the problem of thermomechanics for the considered electroconductive cylinder under the AMRI action.

Numerical analysis of the obtained solution was done for the electroconductive cylinder made of steel H18N9T with radiuses $r_{0}=$ $19 \cdot 10^{-3} \mathrm{~m}, r_{1}=21 \cdot 10^{-2} \mathrm{~m}$. The AMRI duration $\tau_{i}$ assumed to be $\tau_{i}=10^{-3} \mathrm{~s}, \tau_{i}=10^{-4} \mathrm{~s}$, $\tau_{i}=10^{-5} \mathrm{~s}$. The parameters $\beta_{1}$ and $\beta_{2}$ were selected so that $\tau_{\text {iner }} / \tau_{\text {decr }} \approx 0.1$.

The eigen frequencies of mechanical vibrations of the cylinder in connected and nonconnected problem formulations were analyzed based on the characteristic equation (25).

Putting $\varepsilon_{*}=0$ in this equation, we get the known equation to determine eigen frequencies in the case of nonconnected problem of thermomechanics for the hollow electroconductive cylinder.

For the selected cylinder parameters, the following values of the first two eigen frequencies

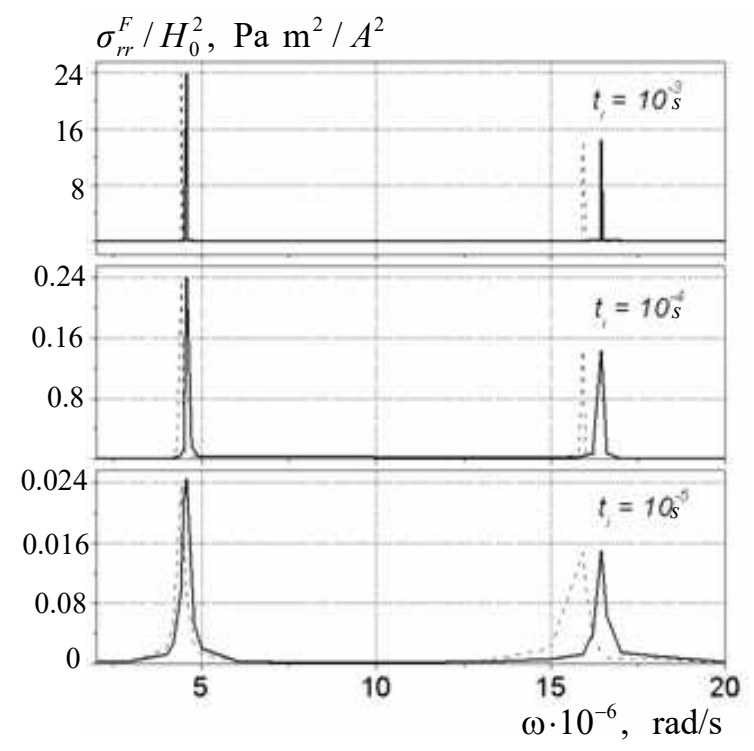

Fig. 1. Amplitude-frequency characteristics of stresses $\sigma_{\mathrm{rr}}^{F}$ in cylinder under the radioimpulse action. 
of mechanical vibration $\omega_{v s}(s=1,2)$ in the case of nonconnected

$$
\omega_{r_{1}}=8.76 \cdot 10^{6} \mathrm{rad} / \mathrm{s} ; \quad \omega_{r_{2}}=31.52 \cdot 10^{6} \mathrm{rad} / \mathrm{s}
$$

and connected

$$
\omega_{r_{1}}^{*}=8.96 \cdot 10^{6} \mathrm{rad} / \mathrm{s} ; \quad \omega_{r_{2}}^{*}=32.46 \cdot 10^{6} \mathrm{rad} / \mathrm{s}
$$

statements of thermomechanics problem were obtained.

The study of amplitude-frequency characteristics (AFC) [12] of radial stresses $\sigma_{r r}(r, t)$ for selected AMRI durations was made, the research results are presented in Fig. 1.

The solid curves correspond to AFC of radial stress in connected and dashed lines- in non-connected case. We obtained that on resonant frequencies of EMF equal $\omega_{r s} \approx 1 / 2 \omega_{v s}$ and $\omega_{r s}^{*} \approx 1 / 2 \omega_{v s}^{*}$ that is, in non-connected

$$
\omega_{r_{1}}=4.38 \cdot 10^{6} \mathrm{rad} / \mathrm{s} ; \quad \omega_{r_{2}}=15.76 \cdot 10^{6} \mathrm{rad} / \mathrm{s}
$$

and connected

$$
\omega_{r_{1}}^{*}=4.48 \cdot 10^{6} \mathrm{rad} / \mathrm{s} ; \quad \omega_{r_{2}}^{*}=16.23 \cdot 10^{6} \mathrm{rad} / \mathrm{s}
$$

statements of the problem of thermomechanics we have the shifts of AFC peaks. The maximum values of radial stresses in the case of connected and non-connected thermomechanic problems practically coincide.

\section{Conclusions}

The application of approximations for all determining functions with respect to the radial variable by cubic polynomials makes it possible to reduce solving the corresponding initial-boundary value problems for these functions, which are the components of the complex coupled problem of thermomechanics for an electroconductive hollow cylinder under homogeneous non-stationary electromagnetic action, to the corresponding Cauchy problem for integral characteristics for these functions.

The solutions of the Cauchy problem in the form of functions convolution, which describe the uniform solutions and the limit values of the determining functions over the whole time period of nonstationary electromagnetic action were found.

The study of the AFC radial stresses shows that their peak values increase linearly with the increase of radioimpulse duration, for connected and non-connected thermomechanics problems are practically the same.

[1] Batyigin Yu. V., Lavinsky V. I., Himenko L. T. Impulsnyie magnitnyie polya dlya progressivnyih tehnologij [Impulse magnetic fields for advanced technologies]. Harkov, MOST-Tornado Publ., 288 p. (2003), (in Russian).

[2] Tiermoprugost eliectroprovodnykh tiel [Thermoelasticity of conductive bodies] J.S.Podsrigach, Y. I. Burak, A. R. Hachkevych, L. V. Chernjavska. Kyiv, Naukova dumka. (1977), (in Russian).

[3] Silnye i sverhsilnye magnitnyie polia i ikh primenenie [Strong and superstrong magnetic fields and their applications]. Pod red. Herlaha F. Moscow, Mir Publ. (1988), (in Russian).

[4] Knopfel G. Sverkhsilnyie impulsnyie magnitnyie polia. Metody generacii i fizicheskie effecty, sviazannyie s sozdaniem impulsnykh polej megaerstednogo diapazona [Superstrong impulse magnetic fields. Methods of generation and physical effects, connected with action of impulse fields of megaersted diapasone]. Moscow, Mir. (1972), (in Russian).

[5] Tamm I. E. Osnovy teorii electrichestva [Fundamentals of electricity theory]. Moscow, Nauka. (1976), (in Russian).

[6] Moon F. C. Magnetosolid mechanics. New York, Willey. (1984).

[7] Gribanov V.F. Sviazannyiie i dinamicheskiie zadachi termouprugosti [Connected and dynamical problems of thermoelasticity]. Moscow, Mashynostroeniie. (1984), (in Russian). 
[8] Pyriev Yu. O. Poshirennia hvil u pruzhnikh seredovishchakh z urakhuvanniam sviaznosti fizikomekhanichnikh poliv [Wave distribution in elastic medium considering connectivity of physico-mechanical fields]. Lviv, Svit. (1988), (in Ukranian).

[9] Hachkevych O.R., Musij R. S., Stasiuk H. B. Zviazana zadacha termomekhaniky dlia elektroprovidnoho sharu za odnoridnoij impulsnoij diji [Connected problem of thermomechanics for electroconductive layer under homogeneous impulse action]. Fiz.-meckh. mekhanika materialiv. 45(4), 60-66 (2009), (in Ukranian).

[10] Musiy R. S. Dynamichni zadachi termomekhaniky electroprovidnykh til kanonichnoji formy [Dynamic problems of thermomechanics for conductive bodies of canonical form]. Lviv, Rastr-7 Publ. (2010), (in Ukranian).

[11] Hachkevych O. R., Musij R. S., Tarlakovskyi D. V. Termomekhanika neferomahnitnykh elektroprovidnykh elektromakhnitnykh poliv z moduliatsiieiu amplitudy [The therrmomechanics of nonferromagnetic conductive bodies for the action of the pulse electromagnetic fields with amplitude modulation]. Lviv, SPOLOM. (2011), (in Ukranian).

[12] Musij R. S., Shymchak Y. J. The methodology of investigation of resonance phenomena in nonferromagnetic electroconductive solids of canonical form under electromagnetic action with impulse modulating signal. Fizyko-matematychne modeliuvannia ta infopmatsiini tekhnolohuu [Physico-mathematical modelling and informational technologies]. 8, 113-129 (2008), (in Ukranian).

\title{
Розв'язки зв'язаної задачі термомеханіки для електропровідного порожнистого циліндра за нестаціонарної електромагнітної дії
}

\author{
Мусій Р., Дрогомирецька Х., Орищишин О. \\ Національний університет "Львівська політехніка" \\ вул. С. Бандери, 12, 79013, Лъвів, Україна
}

\begin{abstract}
Сформульовано плоску осесиметричну зв'язану динамічну задачу термомеханіки для електропровідного порожнистого циліндра за однорідної нестаціонарної електромагнітної дії. Для побудови її розв'язку використано апроксимацію визначальних функцій - осьової комппоненти вектора напруженості магнітного поля, температури та радіальної компоненти вектора переміщень за радіальною змінною - кубічними поліномами. У результаті вихідні початково-крайові задачі на визначальні функції зведено до задач Коші за часовою змінною на інтегральні характеристики цих функцій. Отримано вирази інтегральних характеристик у вигляді згорток функцій, що описують однорідні розв'язки та задані граничні значення визначальних функцій. Як приклад числово проаналізовано амплітудно-частотні характеристики радіальних напружень у цьому циліндрі за врахування зв'язності полів температури і переміщень і без такого врахування.
\end{abstract}

Ключові слова: зв'язана задача термомеханіки; порожнистий електропровідний ииліндр; нестаціонарна електромагнітна діл; апроксимаціл; інтегральні характеристики.

2000 MSC: $74 \mathrm{H} 10$

УдК: 539.3 